\title{
RESULTS FROM LABORATORY TESTS OF NEW ELECTRIC BRAKE PROTOTYPE
}

\author{
Pawel Grygorcewicz \\ Lukasiewicz Research Network - Institute of Aviation \\ Krakowska Av. 110/114, 02-256 Warsaw, Poland \\ tel.: +48228460011 ext. 657, fax: +48 943426753 \\ e-mail: pawel.grygorcewicz@ilot.edu.pl
}

\begin{abstract}
The main idea of this article was to compare the results of new design electric brake to the older version of hydraulic brake in laboratory tests. The energy of braking should be very similar due to the same mass of the airplane. That is why the laboratory tests of both brakes were took place in the same stand. Of course, the parameters were similar but not at all. The main idea was to create the solution, which could be used in vehicle like airplane. The electric brakes could replace traditional hydraulic brake solution. The results could be interesting for every researcher who is interested in brakes. Other important idea of this article was to describe the tests of new electric brake prototype. The purpose of the tests was to check designing of electric brakes. The electric brake prototype should ensure sufficient efficiency, safety, reliability and durability during braking, which is required in certification processes and is particularly important when researching innovative solutions. It was really important to verify the design and check the parameters. Of course, there is really important to remember that in every new type of the prototype solutions there are many pros and cons, which are typical only for considered design. Nowadays every electric brake design is different because there is a lot of new concept.
\end{abstract}

Keywords: laboratory test, electric brake, braking process

\section{Introduction}

The electric brake has been designed since the idea, conception to the last prototype phase. After the assembly phase, the electric brake was mounted on the test stand and the tests were conducted. The purpose of the tests was to check designing of electric brakes. The electric brake prototype should ensure sufficient efficiency, safety, reliability and durability during braking, which are required in certification processes and this is particularly important when researching innovative solutions. It was really important to verify the design and check the parameters [2].

In our examples, there were tested two brakes electric and hydraulic. Both solutions could be used in the same type of airplane. The hydraulic brake was tested in the past.

\section{Parameters and results of electric brake tests}

Firstly a series of initial braking was performed. The initial braking tests were carried out to optimize the surface area of interaction of friction linings and brake disc. The frictional contact surface area by lapping was as close as possible to the geometric maximum, by levelling the shape errors (waviness, non-parallelism etc.) and excessive roughness, through which frictional cooperation takes place only on a part of the surface - roughness peaks [4].

The tests were started with the small treadmill energy. Firstly the tests were started carefully due to designing functionality was tested. The full scale designing correctness of all parts was verify and the idea of designing this solution of electric brake was checked. Then the correct parameters were selected and set. There was possibility to change the braking characteristics for example to increase efficiency or lifespan of linings. Later the energy increased even to the takeoff energy, which is the highest energy for brakes in airplanes after landing. 
Data used for trials:

$P=349$ daN $\quad-$ static load of the wheel,

$I_{b}=588 \mathrm{kgm}^{2} \quad-$ inertia of the treadmill,

$p_{o p}=0.38 \mathrm{MPa}$ - tire pressure,

$m_{s}=1117 \mathrm{~kg} \quad-$ mass of the aircraft,

$V_{\text {so }}=113.3 \mathrm{~km} / \mathrm{h}-$ stall speed,

$E_{h}[\mathrm{~J}] \quad$ - braking energy,

$a_{s}[\mathrm{rpm} / \mathrm{s}] \quad-$ acceleration of engine rotation,

$a_{p}[\mathrm{rpm} / \mathrm{s}] \quad-$ engine speed delay,

$n[\mathrm{rpm}] \quad-$ speed of the treadmill,

$t[\mathrm{~s}] \quad-$ braking time,

$T_{\text {disc }}\left[{ }^{\circ} \mathrm{C}\right] \quad-$ brake disc temperature.

During the tests, the temperature was checked after the every trial by pyrometer. In different tests, the temperature of disc was changed because the energy of every test increased. The results are shown in Tab. 1 and 2.

Tab. 1. Results of tested electric brake

\begin{tabular}{|c|c|c|c|c|c|c|c|l|}
\hline No. & $\begin{array}{c}P \\
{[\mathrm{daN}]}\end{array}$ & $\begin{array}{c}I_{b} \\
{\left[\mathrm{kgm}^{2}\right]}\end{array}$ & $\begin{array}{c}E_{h} \\
{[\mathrm{~J}]}\end{array}$ & $\begin{array}{c}a_{s} \\
{[\mathrm{rpm} / \mathrm{s}]}\end{array}$ & $\begin{array}{c}n \\
{[\mathrm{rpm}]}\end{array}$ & $\begin{array}{c}t \\
{[\mathrm{~s}]}\end{array}$ & $\begin{array}{c}T_{\text {disc }} \\
{\left[{ }^{\circ} \mathrm{C}\right]}\end{array}$ & Comments \\
\hline 1 & 349 & 588 & & 3000 & 29 & & 27 & \\
\hline 2 & 349 & 588 & & 3000 & 22 & & 27 & \\
\hline 3 & 349 & 588 & & 3000 & 44 & 3.5 & 30 & \\
\hline 4 & 349 & 588 & 8632.62 & 3000 & 50 & 4 & 30 & \\
\hline 5 & 349 & 588 & 8632.62 & 3000 & 55 & & 37.5 & Without reg. \\
\hline 6 & 349 & 588 & & 3000 & 300 & & & Free run \\
\hline 7 & 349 & 588 & & 3000 & 300 & 850 & & Free run \\
\hline 8 & 349 & 588 & & 3000 & 50 & 45 & & Free run \\
\hline 9 & 349 & 588 & & 3000 & 50 & 46 & & Free run \\
\hline 10 & 349 & 588 & & 3000 & 50 & 46 & & Free run \\
\hline 11 & 349 & 588 & 19423.40 & 3000 & 78 & 8 & 46 & \\
\hline 12 & 349 & 588 & 34530.49 & 3000 & 104 & 8 & 62 & \\
\hline 14 & 349 & 588 & 34530.49 & 3000 & 104 & 8 & 59.5 & \\
\hline 15 & 349 & 588 & 53953.89 & 3000 & 130 & 10 & 60 & \\
\hline 16 & 349 & 588 & 77693.61 & 3000 & 156 & 14 & 93 & \\
\hline 17 & 349 & 588 & 105749.63 & 3000 & 182 & 14 & 112 & \\
\hline 18 & 349 & 588 & 138121.96 & 3000 & 207 & 16 & 140 & \\
\hline 19 & 349 & 588 & 174810.61 & 3000 & 233 & 16 & 144 & \\
\hline 20 & 349 & 588 & 215815.57 & 3000 & 259 & 20 & 175 & \\
\hline 21 & 349 & 588 & 276558.28 & 3000 & 294 & 20 & 212 & Take off speed \\
\hline 22 & 349 & 588 & 34530.49 & 1000 & 104 & 8 & 50 & \\
\hline 23 & 349 & 588 & 77693.61 & 1000 & 156 & 10 & 84.5 & \\
\hline 24 & 349 & 588 & 138121.96 & 1000 & 207 & 14 & 131 & \\
\hline 25 & 349 & 588 & 34530.49 & 5000 & 104 & 6 & 44.7 & \\
\hline 26 & 349 & 588 & 77693.61 & 5000 & 156 & 8 & 75 & \\
\hline 27 & 349 & 588 & 138121.96 & 5000 & 207 & 11 & 134.8 & \\
\hline 28 & 349 & 588 & 174810.61 & 5000 & 233 & 14 & 167 & \\
\hline 29 & 349 & 588 & 215815.57 & 5000 & 259 & 15 & 190 & \\
\hline 30 & 349 & 588 & 276558.28 & 5000 & 294 & 17 & 270 & Take off speed \\
\hline
\end{tabular}


Results from Laboratory Tests of New Electric Brake Prototype

Tab. 2. Results of tested electric brake with braking moment measurement

\begin{tabular}{c|c|c|c|c|c|c|c|c|c}
\hline No. & $\begin{array}{c}P \\
{[\mathrm{daN}]}\end{array}$ & $\begin{array}{c}I_{b} \\
{\left[\mathrm{kgm}^{2}\right]}\end{array}$ & $\begin{array}{c}E_{h} \\
{[\mathrm{~J}]}\end{array}$ & $\begin{array}{c}a_{s} \\
{[\mathrm{rpm} / \mathrm{s}]}\end{array}$ & $\begin{array}{c}n \\
{[\mathrm{rpm}]}\end{array}$ & $\begin{array}{c}t \\
{[\mathrm{~s}]}\end{array}$ & $\begin{array}{c}T_{\text {disc }} \\
{\left[{ }^{\circ} \mathrm{C}\right]}\end{array}$ & $\begin{array}{c}M_{h \max } \\
{[\mathrm{daNm}]}\end{array}$ & Comments \\
\hline 31 & 349 & 588 & 34530 & 5000 & 104 & 7 & 50 & 200 & \\
\hline 32 & 349 & 588 & 53953 & 5000 & 130 & 8 & 87.5 & 200 & \\
\hline 33 & 349 & 588 & 77693 & 5000 & 156 & 8 & 91.6 & 200 & \\
\hline 34 & 349 & 588 & 105749 & 5000 & 182 & 10 & 130.5 & 190 & \\
\hline 35 & 349 & 588 & 105794 & 5000 & 182 & 10 & 135.7 & 200 & \\
\hline 36 & 349 & 588 & 138121 & 5000 & 207 & 12 & 156 & 200 & \\
\hline 37 & 349 & 588 & 174810 & 5000 & 233 & 12 & 171 & 210 & \\
\hline 38 & 349 & 588 & 215815 & 5000 & 259 & 15 & 212 & 220 & \\
\hline 39 & 349 & 588 & 276558 & 5000 & 300 & 16 & 270 & 220 & Take off speed \\
\hline 40 & 349 & 588 & 34530 & 3000 & 104 & 6 & 55 & 230 & \\
\hline 41 & 349 & 588 & 53953 & 3000 & 130 & 7 & 76 & 230 & \\
\hline 42 & 349 & 588 & 77693 & 3000 & 156 & 9 & 94.7 & 210 & \\
\hline 43 & 349 & 588 & 34530 & 6000 & 104 & 6 & 60 & 240 & \\
\hline 44 & 349 & 588 & 53953 & 6000 & 130 & 8 & 79 & 240 & \\
\hline 45 & 349 & 588 & 77693 & 6000 & 156 & 9 & 99 & 230 & \\
\hline 46 & 349 & 588 & 34530 & 8000 & 104 & 5 & 65 & 240 & \\
\hline 47 & 349 & 588 & 53953 & 8000 & 130 & 7 & 87 & 230 & \\
\hline 48 & 349 & 588 & 77693 & 8000 & 156 & 9 & 92 & 220 & \\
\hline 49 & 349 & 588 & 105749 & 8000 & 182 & - & 105 & 200 & Multiple braking \\
\hline 50 & 349 & 294 & 34530 & 8000 & 147 & 2 & 32 & 210 & \\
\hline 51 & 349 & 294 & 53953 & 5000 & 183 & 4 & 42 & 220 & \\
\hline 52 & 349 & 294 & 77693 & 5000 & 220 & 5 & 75 & 200 & \\
\hline & & & & & & & & & \\
\hline
\end{tabular}

In the Fig. 1 there was shown the stand in laboratory. The stand parts and equipment was assembled based on the 3D model of full prototype, which was shown in Fig. 2.

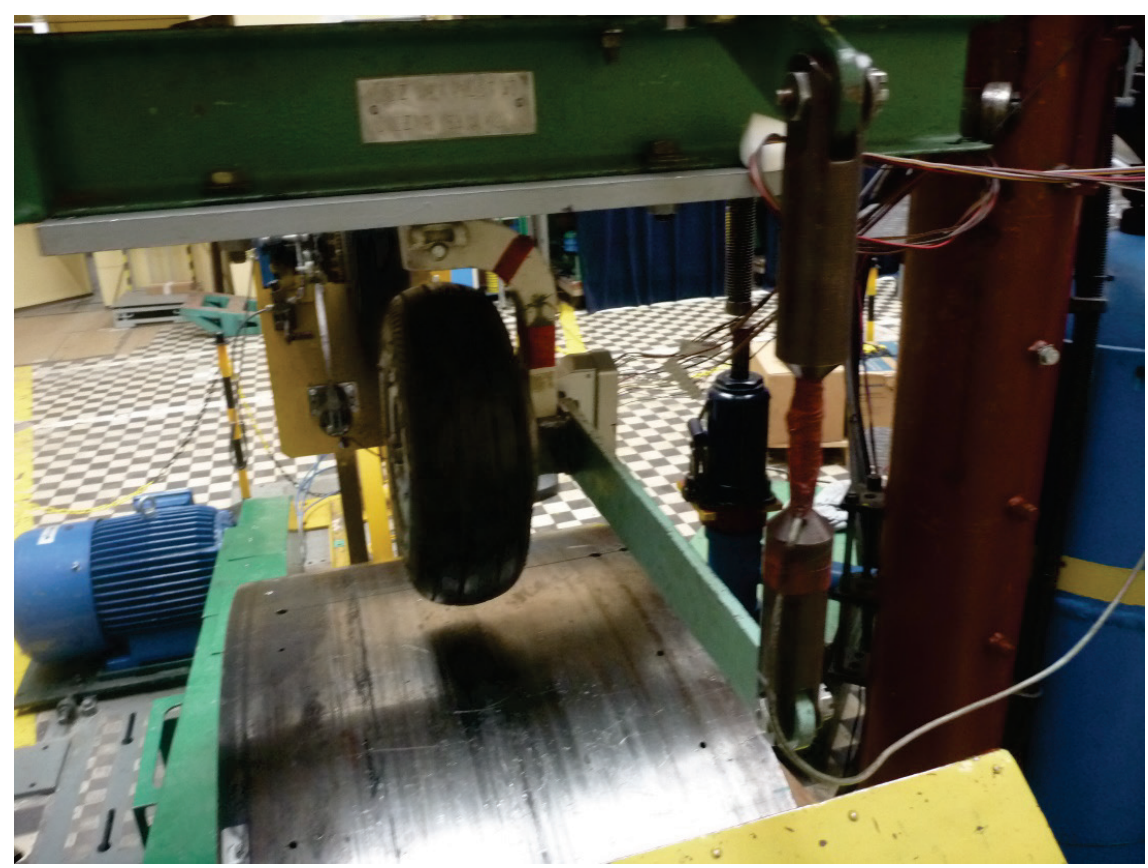

Fig. 1. View of the brake on stand 


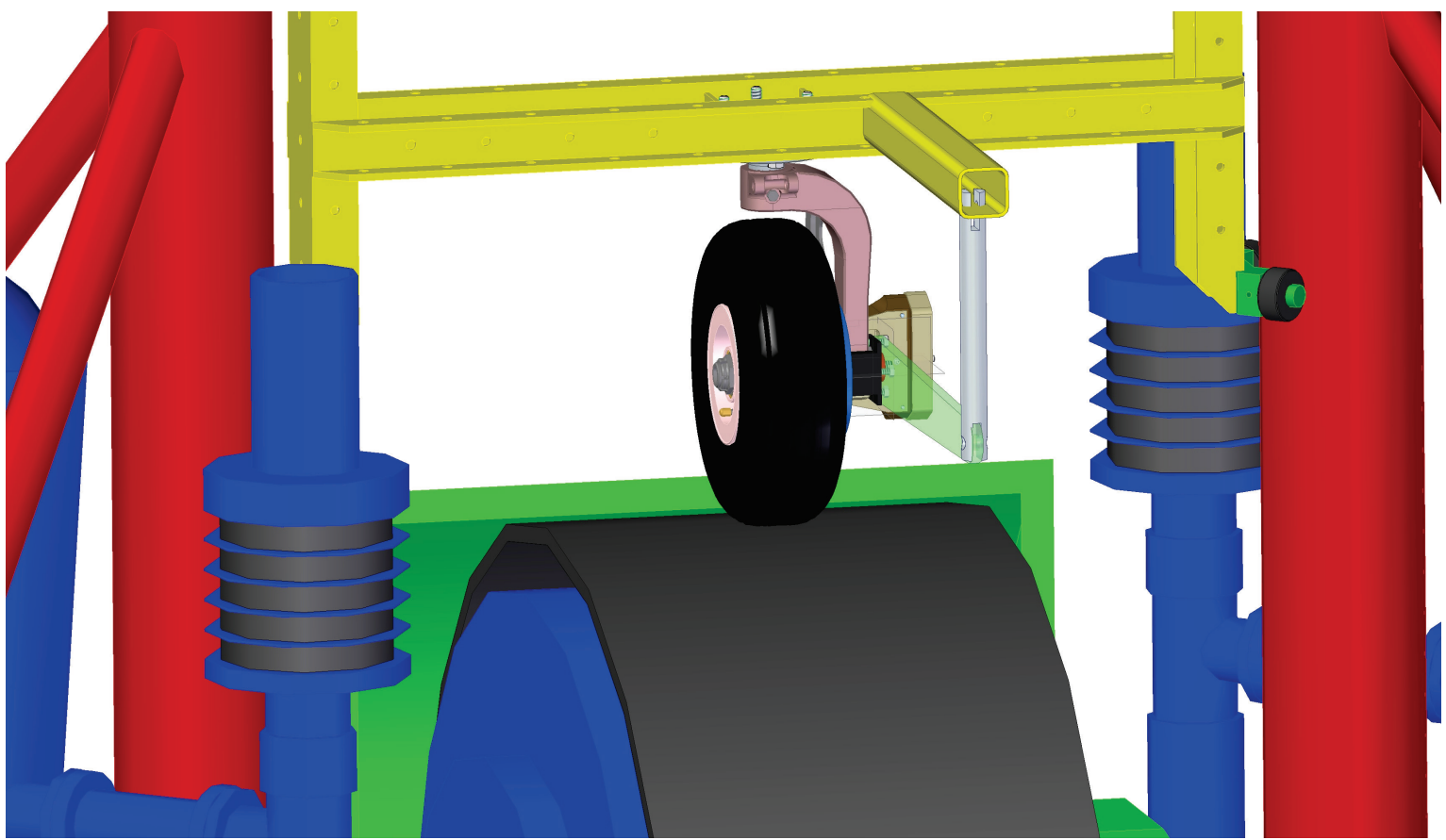

Fig. 2. View of the brake on stand - 3D model

The all fifty-two results from tests of electric brake were shown in these tables. Since thirtyone test, the moment of braking has been measured.

The typical graph from tests was shown in Fig. 3. In this example, the trial No. 29 (Tab. 1) was taken into account to show how it was looked. The speed of treadmill (red and navy blue colour on graph - two different sensors were used to ensure the results were good enough) decreased from about $259 \mathrm{rpm}$ to $0 \mathrm{rpm}$. The time of braking was about $15 \mathrm{~s}$.

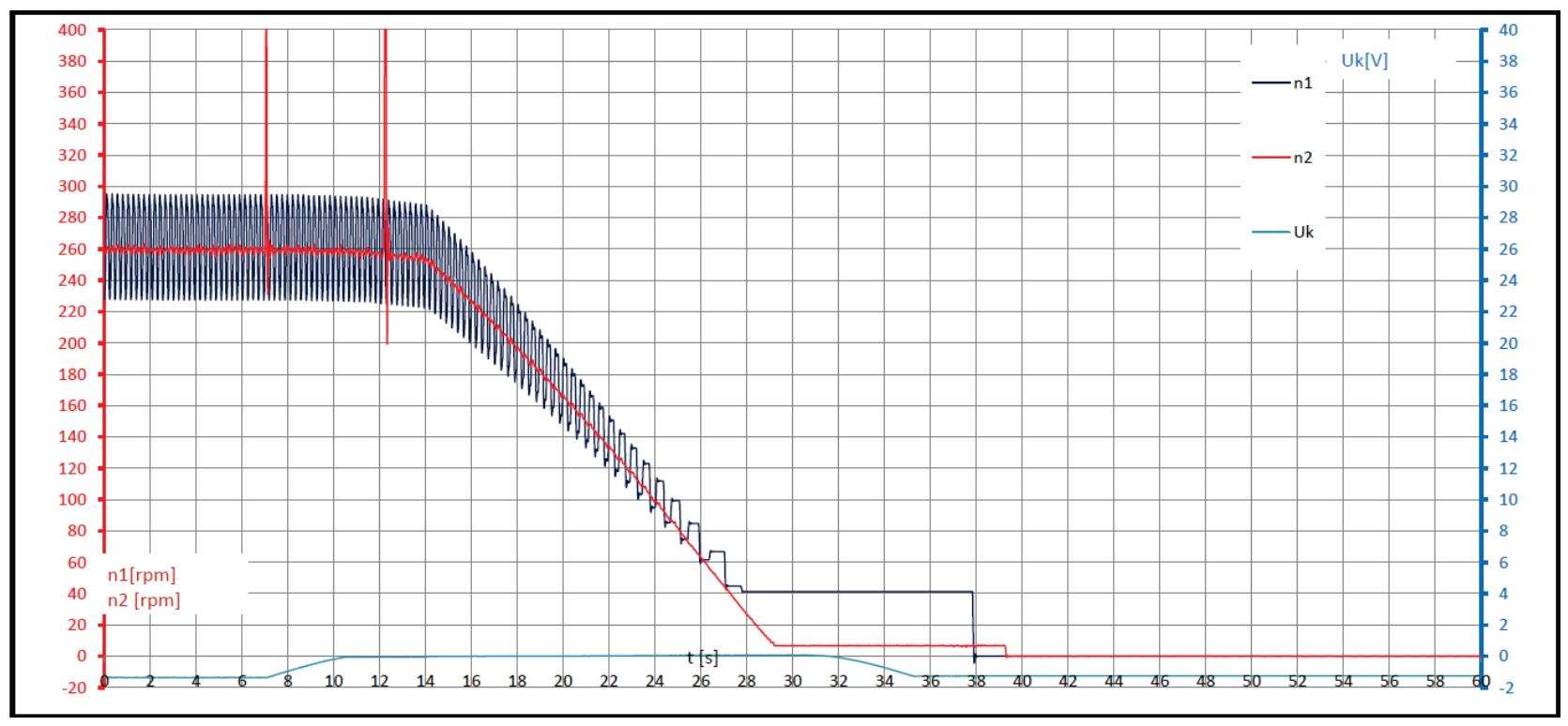

Fig. 3. Graph from brake test on Młot $3 T$ stand for $n=259 \mathrm{rpm}$

In the second example, the trial No. 37 (Tab. 2) was taken into account to show how it was looked. The speed of treadmill (red and navy blue colour on graph - two different sensors were used to ensure the results were good enough) decreased from about $233 \mathrm{rpm}$ to $0 \mathrm{rpm}$. The time of braking was about $12 \mathrm{~s}$. The braking moment (green line on graph) was about $210 \mathrm{daNm}$. The braking moment on graph was only during braking process. This was shown in Fig. 4. 


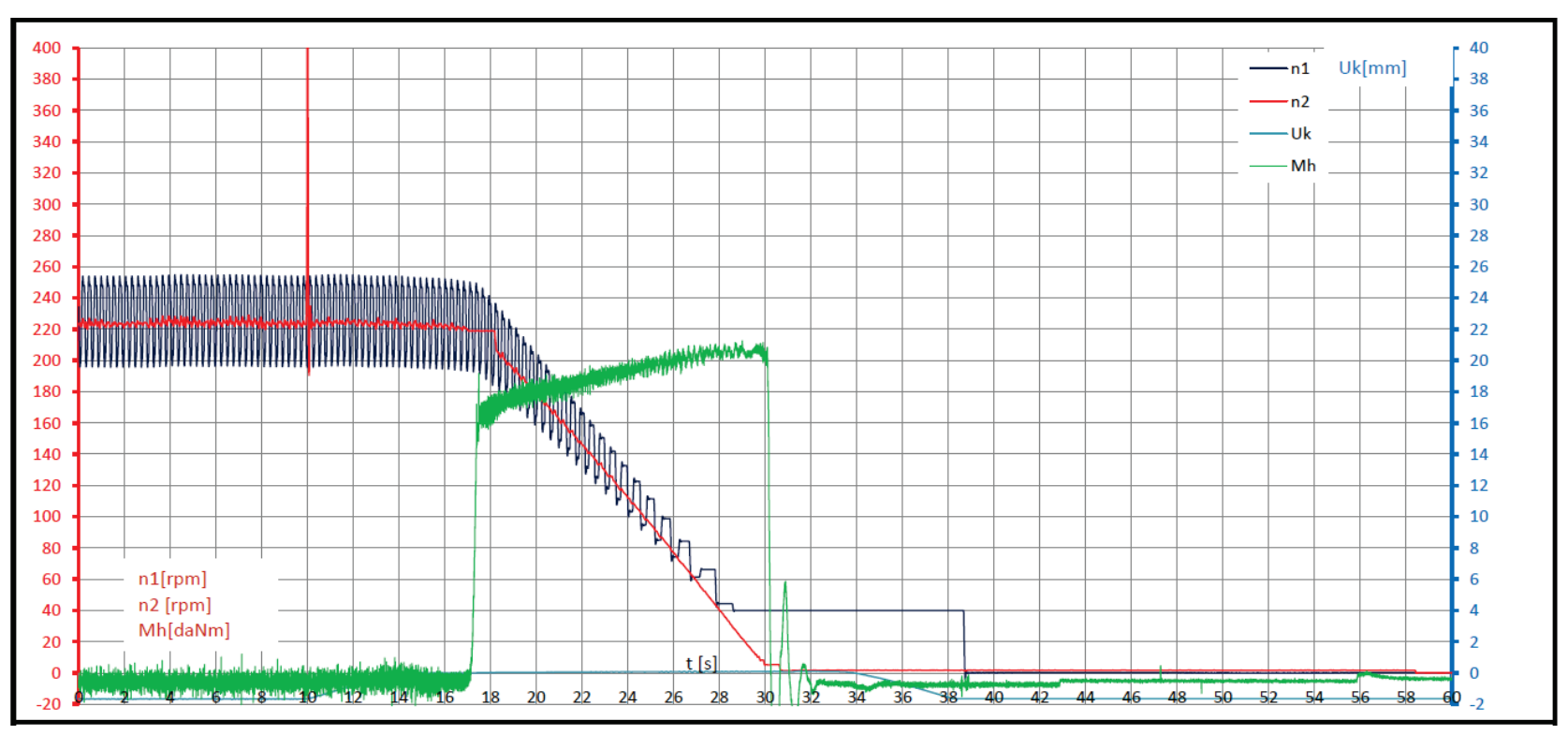

Fig. 4. Graph from brake test on Młot $3 T$ stand for $n=233 \mathrm{rpm}$

The measurement of the braking moment gave the answer of the piston force in brake, which were used to braking on the linings. The calculated force was nearly the same like from tests. The special equipment was designed to measure the braking moment. The wheel with brake assembly was redesigned only for measure the moment of braking (Fig. 1).

\section{Parameters and results of hydraulic brake test}

In the past the tests of hydraulic brake was took place to the I-23 airplane. The parameters of the tests:

$P=349 \mathrm{daN}(328 \mathrm{daN}$ for $M=1050 \mathrm{~kg})$ - static load of the wheel,

$I_{b}=294 \mathrm{kgm}^{2}-$ inertia of the treadmill,

$V_{p}=113.3 \mathrm{~km} / \mathrm{h}=31.47 \mathrm{~m} / \mathrm{s}($ e.g. $=430 \mathrm{rpm})-$ stall speed,

$p_{h}=2.94,3.92,4.91 \mathrm{MPa}$ - braking pressure,

$p_{\text {op }}=0.38 \mathrm{MPa}$ - tire pressure,

$M=1117 \mathrm{~kg} \quad-$ mass,

$n$ [rpm] - speed of the treadmill,

$t[\mathrm{~s}] \quad-$ braking time,

$T_{\text {disc }}\left[{ }^{\circ} \mathrm{C}\right] \quad-$ brake disc temperature.

Tab. 3. Results of tested hydraulic brake

\begin{tabular}{c|c|c|c|c|c}
\hline No. & $\begin{array}{c}\text { Energy of braking } \\
E_{h}[\mathrm{~J}]\end{array}$ & $\begin{array}{c}\text { Braking pressure } \\
p_{h}[\mathrm{MPa}]\end{array}$ & $\begin{array}{c}\text { Braking time } \\
t[\mathrm{~s}]\end{array}$ & $\begin{array}{c}\text { Temperature of disc brake } \\
T\left[{ }^{\circ} \mathrm{C}\right]\end{array}$ & $\mathrm{n}[\mathrm{rpm}]$ \\
\hline 1 & 276597 & 2.94 & 10 & 417 & $113-430$ \\
\hline 2 & 276597 & 2.94 & 10.2 & 414 & $113-430$ \\
\hline 3 & 276597 & 2.94 & 10.1 & 434 & $113-430$ \\
\hline 4 & 276597 & 3.92 & 9 & 390 & $113-430$ \\
\hline 5 & 276597 & 3.92 & 8.5 & 433 & $113-430$ \\
\hline 6 & 276597 & 3.92 & 8 & 440 & $113-430$ \\
\hline 7 & 276597 & 4.91 & 7.4 & 415 & $113-430$ \\
\hline 8 & 276597 & 4.91 & 7.1 & 429 & $113-430$ \\
\hline 9 & 276597 & 4.91 & 7 & 430 & $113-430$ \\
\hline
\end{tabular}


The tests were carried out with the highest possible energy. This energy was calculated for the airplanes energy after landing which take place during braking. The stand energy, which brake needed to stop was the same. The braking pressure was different which decreased the braking time and braking distance.

The braking time, which has influence to the braking distance, is nearly the same. The time of braking was $10 \mathrm{~s}$ in hydraulic brake and in electric brake; it was $16 \mathrm{~s}$ in the best test. The parameters were compared only for braking with maximal energy due to the tests were conducted only for this energy in hydraulic brake. The temperature of disc brake was higher in hydraulic brake.

The maximal force possibilities of the electric brake were not used due to complex of the tests and multiple issues, which the designers wanted to check. There was a possibility to create the braking characteristics by changing the electric brake parameters.

If the braking characteristics were change by increasing the motors brake parameters, the efficiency would have been better and the braking distance decreased.

\section{Summary}

The methods of the testing new prototype electric brake and hydraulic brake were the same. In the same laboratory stand were carried out all the tests. Final analysis of the electric brake system during the braking showed there was no very significant difference between both solutions. The results showed that there is possibility to use the electric brake in airplane with nearly the same efficiency as hydraulic brake. Nowadays where every hydraulic system in airplane is replaced by electric system, this option could be very useful and popular for designers.

The analysis of the electric brake showed that there is huge potential of controlling the braking characteristic and improve the efficiency to the needs.

All of the tests and analysis described in this article were performed in the Landing Gear Laboratory of Institute of Aviation in Warsaw.

\section{References}

[1] Currey, N. S., Aircraft Landing Gear Design Principles and Practices, Washington AIAA, 1988.

[2] Grygorcewicz, P. Paprzycki, I., Stanowisko i wytyczne do badań ABS w samolotach, Logistyka, 2015.

[3] Grygorcewicz, P., Issues During Assembly New Type of Electric Brake Prototype and Initial Tests of Individual Components, Journal of KONES, Vo. 25, No. 3, pp. 213-218, 2018.

[4] Grygorcewicz, P., Skorupka, Z, Badanie laboratoryjne hamulców ciernych w laboratorium badań podwozi lotniczych, TTS Technika Transportu Szynowego, 2013.

Manuscript received 17 June 2019; approved for printing 23 September 2019 